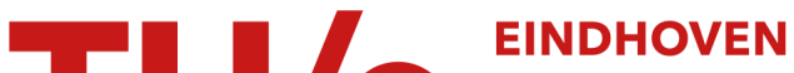 \\ UNIVERSITY OF \\ TECHNOLOGY
}

\section{Incentives-based ancillary services for power system integrity}

\section{Citation for published version (APA):}

Bosch, van den, P. P. J., Jokic, A., Frunt, J., Kling, W. L., Nobel, F., Boonekamp, P., Boer, de, W., \& Hermans, R. M. (2009). Incentives-based ancillary services for power system integrity. In Proceedings of the 6th International Conference on the European Energy Market (EEM 2009) 27-29 May 2009, Leuven, Belgium (pp. 1198-1/7). Institute of Electrical and Electronics Engineers. https://doi.org/10.1109/EEM.2009.5207180

DOI:

10.1109/EEM.2009.5207180

Document status and date:

Published: 01/01/2009

\section{Document Version:}

Publisher's PDF, also known as Version of Record (includes final page, issue and volume numbers)

\section{Please check the document version of this publication:}

- A submitted manuscript is the version of the article upon submission and before peer-review. There can be important differences between the submitted version and the official published version of record. People interested in the research are advised to contact the author for the final version of the publication, or visit the $\mathrm{DOI}$ to the publisher's website.

- The final author version and the galley proof are versions of the publication after peer review.

- The final published version features the final layout of the paper including the volume, issue and page numbers.

Link to publication

\section{General rights}

Copyright and moral rights for the publications made accessible in the public portal are retained by the authors and/or other copyright owners and it is a condition of accessing publications that users recognise and abide by the legal requirements associated with these rights.

- Users may download and print one copy of any publication from the public portal for the purpose of private study or research.

- You may not further distribute the material or use it for any profit-making activity or commercial gain

- You may freely distribute the URL identifying the publication in the public portal.

If the publication is distributed under the terms of Article $25 f a$ of the Dutch Copyright Act, indicated by the "Taverne" license above, please follow below link for the End User Agreement:

www.tue.nl/taverne

Take down policy

If you believe that this document breaches copyright please contact us at:

openaccess@tue.nl

providing details and we will investigate your claim. 


\title{
Incentives-based ancillary services for power system integrity
}

\author{
P.P.J. van den Bosch, Member IEEE1, A. Jokic Member IEEE, J. Frunt, Student Member, IEEE, W.L. \\ Kling, Member IEEE, F. Nobel, P. Boonekamp, W. de Boer, R.M. Hermans, Student member IEEE
}

\begin{abstract}
A reliable and efficient power system is a necessity for any industrialized society. Governments have to enforce regulations to guarantee that such a power system, in spite of many competing stakeholders, participants, companies and regulating agencies can be operational. This paper analyzes the present arrangements and the future requirements to be posed on incentives and regulation for ancillary services for power imbalance to guarantee a reliable and efficient operation of power systems in a market environment with responsive, reliable and accountable but also competing prosumers, a large penetration of renewables and continent spanning transmission networks.
\end{abstract}

Index Terms-Ancillary services, control of power systems, primary control, secondary control, price-based control

\section{INTRODUCTION}

We assume that there are sufficient incentives and proper arrangements for creating and extending the infrastructure, that there are transparent and open markets for day-ahead trading of energy based on predictions of available power sources and demand. These markets are based on Balance Responsible Parties (BRP) which are the only entities that are allowed and capable to trade on these markets. As such they are reliable and accountable for their operations, so trustworthy partners. These BRPs make predictions of both their own available production capacity and their own demand and their costs (costs and/or benefits) associated with producing and supplying energy. For achieving a better economic and/or technical solution, energy can be sold/bought bilaterally or on day-ahead markets. Based on their bids on these (future) energy markets, they can decide how much energy they will sell/buy on these markets to create an energy balance among their production, demand and net energy bought/sold from the markets, in all time periods of some future time interval (e.g. the next day). Their main incentive is to maximize profits by bidding energy contracts defined by time period, size and price. The market will decide about how

\footnotetext{
${ }^{1}$ This research is being funded by the Dutch research agency SenterNovem as EOS project RegelDuurzaam.

P. P. J. van den Bosch, A. Jokic and R.M. Hermans are with the Control Systems group at the Eindhoven University of Technology, p.p.j.v.d.bosch@tue.nl, P.O.Box 513, 5600MB Eindhoven, The Netherlands.

J. Frunt and W.L. Kling are with the Electrical Power Systems group at the Eindhoven University of Technology.

F. Nobel is with TenneT, the Dutch TSO, in Arnhem.

P. Boonekamp is with APX, the Amsterdam Power eXchange.

W. de Boer is with Kema, energy consultancy in Arnhem.
}

much net energy has to be delivered/received from other BRPs and for which price. These considerations are based on predicted amounts of energy and prices. Uncertainty and disturbances are explicitly not taken into account.

This paper discusses what has to be done, from a systems point of view, to guarantee a reliable and economic operation of the power system in case of uncertainties and disturbances. We will focus on the arrangements, markets and required incentives to deal with Ancillary Services (AS) which are intended for and can cope with uncertainties and unexpected disturbances [1-6]. First the BRP will be better defined and arguments will be given to determine its "optimal" size. Next the present arrangements in the Netherlands will be discussed, analyzed and commented. It will be shown that the present way of dealing with uncertainty and disturbances is neither consistent, nor optimal and not well suited for the challenges of the future $[2,8]$. A discussion is being made about other, more market-based solutions to achieve that goal, namely the ahead markets for ancillary services. The paper concludes with a consistent description of how these markets and their regulation could be organized with some final concluding remarks about the differences compared with present-day solutions.

Notation: We assume that many quantities can be both positive and negative: power [MW] and energy [MWh]: both production $(>0)$ and consumption $(<0)$; capacity $[M W h]$ : energy $(>0,<0)$ kept available as ancillary service waiting to be utilized; prosumer: end-user who can produce (producer) or consume (consumer) electric energy.

\section{BALANCE RESPONSIBLE PARTIES}

A BRP is a reliable, accountable partner in the daily operation of power markets. It has to and is able to represent its own production capacities and demands but also the production and consumption of its prosumers (producers/consumers) which are represented by their BRP on the markets. There are some driving forces that shape the size of the BRPs:

- A single prosumer bears the full responsibility to predict its own future power imbalance. If $\mathrm{n}$ prosumers share their uncertainty and if we can assume that their uncertainties are not correlated, aggregation reduces the relative size of the uncertainty with a factor $\sqrt{ }(1 / n)$, as elucidated in Fig. 1. The more (independent) clients a $\mathrm{BRP}$ has, the smaller the relative uncertainty becomes. 
This is a clear advantage and a considerable incentive for growing as BRP.

- A second incentive to grow is that a large BRP can exercise marketing power in practice. The ultimate profit for a BRP is when it is a monopoly. Then, there is no transparent, open market and no incentive for low prices.
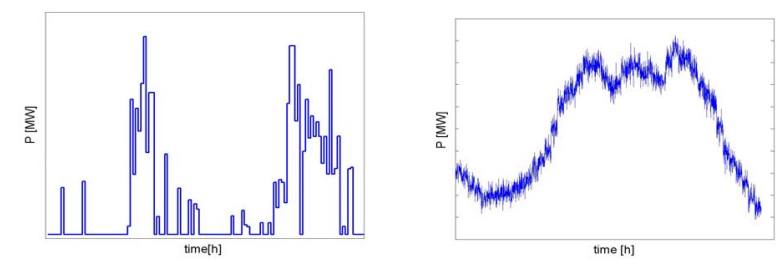

Fig. 1. Power profile of a set of BRPs $(n=1$ left, and $n>>1$ right $)$.

Consequently, a BRP has incentives to grow and almost none to remain small. Growing in size reduces both the uncertainty and, with reduced competition, the pressure to reduce costs.

Conclusion: A competition authority has to take care that transparent and open markets exist by, among others, restricting BRPs to a maximum share of the market.

\section{PRESENT ARRANGEMENTS}

In the Netherlands there is an open market for energy. At the APX (Amsterdam Power eXchange) all BRP's can trade and take care of their energy balance (production + demand + net import). Together with long-lasting and short bilateral contracts and traded energy at the APX (and associated prices) they shape the E-program for the next day. The prices at APX elucidate quite impressive dynamics with, for example, prices as low as $0.01 € / \mathrm{MWh}$ and $500 € / \mathrm{MWh}$ in one year (2007). Before a new day starts, the Dutch TSO (TenneT) validates this E-program with respect to constraints in the network. If any undesired overflow is being detected, this E-program is adjusted. The costs associated with this change owing to congestion management are initially paid by the TSO and are included in the transport tariff. The final program describes clearly the expected energy contributions (+/-) of each BRP in each PTU (Program Time Unit of 15 minutes) for the coming day. Besides this day-ahead market a new, intraday market has been established. It allows additions to the appointments of the APX market up to a few hours before execution. The closer to the moment of execution the less uncertainty and the better the prediction will be. All BRPs have to satisfy their appointments according to the E-program. Not satisfying it, either + or -, will introduce penalties. These penalties are clear incentives to obey the E-program as good as possible. The sum of these penalties are used to pay the BRP which contributes to the request from the TSO for support, so actively supplies the needed AS.

As stated earlier, this trade is based on the amount of energy in a PTU of 15 minutes. The power is measured each 4 seconds and integrated over 15 minutes. This outcome yields the energy. There are no restrictions on the power. Any power

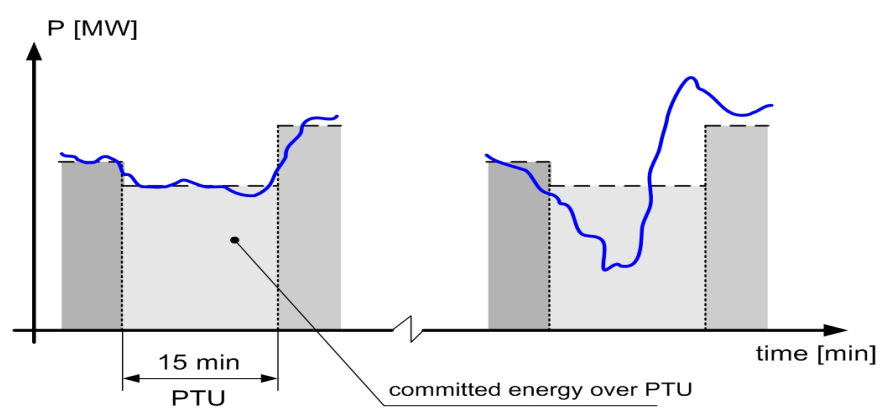

Fig. 2. Power profiles satisfying the same energy requirement of a PTU.

profile is allowed as long as the contracted amount of energy, the time integral of the power over 15 minutes, is satisfied. In Fig. 2 several power profiles are illustrated that all satisfy the required amount of energy in a PTU.

In real-time the predicted values will deviate from their real values. This is clearly true for renewables like solar and wind, but also for loads. In a grid without control at system level any load imbalance $\Delta \mathrm{P}[\mathrm{W}]$ will introduce a constant frequency deviation $\Delta \mathrm{P} / \mathrm{c}_{\mathrm{nw}}[\mathrm{Hz}]$ from the nominal frequency $\mathrm{f}_{\mathrm{o}}(50$ $[\mathrm{Hz}]$ ), with $\mathrm{c}_{\mathrm{nw}}$ the network constant owing to frequencydependent loads, with $\mathrm{c}_{\mathrm{nw}} \approx 6.10^{9}[\mathrm{~W} / \mathrm{Hz}]$ in the UCTE interconnection. The larger the equivalent inertia $J\left[\mathrm{kgm}^{2}\right]$ in the network, the better the disturbance is counteracted (1), for:

$$
\dot{f}(t)=\frac{\Delta P-c_{n w} f(t)}{4 \pi^{2} J f_{o}}
$$

with $\mathrm{J} \approx 1.510^{8}\left[\mathrm{kgm}^{2}\right]$ in the UCTE interconnection. When unpredictability comes in focus, control is the ultimate tool for reducing these deviations. Control requires signals of which both a reference and a measured value are known. Inside a synchronous (AC) power system, the global available frequency $f$ and the local power flows are relevant signals to track the balance.

- The frequency is an indication of the energy balance in the interconnected European grid. When the frequency drifts away from its nominal value of $50[\mathrm{~Hz}]$ it indicates a clear power imbalance.

- The (local) power flows, if measured correctly, yield a clear indication of power imbalance between a BRP and the grid. Both the BRP and the TSO measure this quantity. The BRP will try to adjust, within the PTU, its power to re-establish its negotiated E-program.

- The cross-border power flow can be compared with its required value. Any deviation is an indication for the TSO of a (national) imbalance.

Basically, there are 4 different control actions active to deal with deviations and uncertainties (http://www.etso-net.org).

\section{A. C1: Primary control (PC)}

Each BRP and most likely several of its controllable power sources (+/-) can locally measure the frequency $\mathrm{f}[\mathrm{Hz}]$, detect any deviation $\Delta \mathrm{f}[\mathrm{Hz}]$ from the nominal frequency $\mathrm{f}_{\mathrm{o}}[\mathrm{Hz}]$ and adjusts its power accordingly with a proportional control law: $\Delta \mathrm{P}=\mathrm{c}_{\mathrm{pci}} \cdot \Delta \mathrm{f}[\mathrm{MW}]$. The controller constants $\mathrm{c}_{\mathrm{pci}}[\mathrm{MW} / \mathrm{Hz}]$ are negotiated values agreed upon between the TSO and the BRP. 
This arrangement necessitates that the units participating in the primary control have to operate a certain amount below their limits. Else, in emergency situations, the requested power cannot always be delivered in time. Owing to the enforced PCregulation and the even implementation in the interconnected grid, the sensitivity of the grid for disturbances reduces considerably. The network constant is increased from about 6 (no control) to about $30[\mathrm{GW} / \mathrm{Hz}]$ (between 18 and 45 with PC). This value changes depending on the actual participation of units and the value of their controller constants $c_{p c i}$ $[\mathrm{MW} / \mathrm{Hz}]$. The $1 \%$ margin set by regulation represents a lost opportunity for participating in the energy markets!

Remark 1: As PC requirements are not equally distributed among the BRPs, a BRP has only negative incentives to participate in PC:

- $\quad$ PC introduces lost opportunities for earning in the energy markets.

- $\quad$ PC makes production less predictable, more hectic and so introduces wear and less efficient operations as these units have to react quickly to changes in the frequency.

- PC can enforce that the agreed energy production in a PTU will not meet its target and so the BRP will be penalized for any (positive or negative) deviation.

The amount of the power needed for PC is unilaterally determined by the UCTE.

Remark 2: PC in the Netherlands is active for units larger than $60 \mathrm{MW}$ and is minimal $1 \%$ of $\mathrm{P}_{\text {nom. }}$. All units between 5 and $60 \mathrm{MW}$ should reserve $3 \%$ of their capacity to contribute to $\mathrm{PC}$ if $|\mathrm{df}|>150 \mathrm{mHz}$. The accuracy needed to measure the frequency $\mathrm{f}$ is about $10 \mathrm{mHz}$. Many, but not of the large units, PC loops have a deadband to avoid unwanted participation in the $\mathrm{PC}$ arrangements.

Conclusion PC: As the passive stability (no control) of a grid is too low, PC is an essential ingredient to preserve stability in case of large power imbalances. However, in the Netherlands, a BRP has no incentive and, consequently, has to be enforced to participate in primary control. Not obeying the agreed participation has to be and is penalized, although with low costs. The enforced participation introduced financial losses. There is a monopoly in determining the size (the $1 \%$ and the values of $c_{p c i}$ ) of the power needed for PC. The values of $c_{p c i}$ are not adjusted to the actual network topology, which could introduce not-intended overflow. A nice property of PC is that no human interaction or global communication is necessary to activate PC. It is fully locally measured and autonomously executed as frequency is a global property for the whole network.

\section{B. C2: Secondary control (SC)}

The power grid is divided into several control areas, in general being the national borders. The TSO in a control area measures the cross-border power and energy exchange. Based on this error in the power exchange $(\Delta \mathrm{P})$ and possible frequency deviation $(\Delta \mathrm{f})$ the control area error e is calculated: $\mathrm{e}=\Delta \mathrm{P}+\mathrm{c}_{\mathrm{sc}} \Delta \mathrm{f}[\mathrm{MW}]$, where $\mathrm{c}_{\mathrm{sc}}$ is the system constant of the area. The SC has to reduce this error to zero. The TSO utilizes a PI-controller, which output $\mathrm{P}_{\mathrm{sc}}[\mathrm{MW}]$ indicates how the power set point in the control area has to be changed.
The TSO has a list of BRPs who have shown interest to participate in the SC. They are permanently available or offer bids for an amount of power [MW] with a price [€/MWh]. As soon as a deviation is detected the TSO selects the cheapest bids until the required $\mathrm{P}_{\mathrm{sc}}$ is satisfied. The last accepted bid determines the price for all. This pricing mechanism is called "Marginal Pricing". Other European countries use a different mechanism, for example "Pay as Bid". All BRPs selected have to produce the offered power and receive a price for it, according to the market-price. As the agreed E-program is also adjusted, participating in the SC does not introduce a penalty. If a BRP does not satisfy the required power/energy consistently, the capacity contract will be reduced and/or the TSO will neglect him next time for SC.

In general, SC requires a minimum power rate of $7 \%$ of the maximum power per minute, so in about 15 minutes (1 PTU) the commanded power change has to be realized.

Remark 3: Imbalance prices are self-regulating. BRPs do not exactly know (in real time) if they have positive or negative imbalance. If BRPs increase prices, all other BRPs will follow. Charging high prices for imbalance may cause high costs.

Remark 4: When the TSO commands an increase of the power in the pending PTU, the BRP has only the requirement to increase its energy. This requirement makes no statements about the power profile. So, the demanded power can be delivered more than 10 minutes later than (urgently) needed.

Conclusions SC: The UCTE and the TSO determine, unilaterally, the coefficient $\mathrm{c}_{\mathrm{sc}}$ in the control area error calculation and the requirements $(7 \% / \mathrm{min})$ respectively. There is a single-sided open market for BRPs to participate in the SC. The TSO has to guarantee that sufficient BRPs participate in the SC market to avoid monopolistic behavior and too high prices. The BRPs have an incentive to participate in the $\mathrm{SC}$ as participation yields rewards.

\section{C3: Tertiary control}

After about 15 minutes bilateral contracts can replace the effects of the SC. These contracts are not the responsibility of the TSO. If the area control error still exists after 15 minutes the TSO will continue to demand support from the selected BRPs.

Remark 5: A TSO has to reduce the control area error of the $\mathrm{SC}$ to zero. However, this does not imply that the net energy exchange over a certain time period across the border has satisfied its agreed values. To avoid bills for deviations, the TSO takes care that when such a net energy error has occurred it will be compensated in a next day according to UCTE policies. As prices will not be equal, this action introduces some disturbance in the system.

\section{C4: Time control}

At UCTE level the integral of the frequency is monitored and controlled to keep grid frequency dependent clocks synchronized. If, as a consequence of imbalances the frequency changes from $50[\mathrm{~Hz}]$, these frequency deviations are integrated into a frequency error. Next, the set point of the 
nominal frequency is being adjusted to reduce the frequency error to zero.

Remark 6: TSOs receive the frequency reference $f_{o}$ and send its value to the large BRPs. Time control is implemented in secondary control but the local primary control with notadjusted values of the reference value, will always counteract this.

\section{CONTROL CONSIDERATIONS}

In Fig. 3 the effects of a load disturbance $\Delta \mathrm{P}$ [MW] is elucidated for 5 situations: $\mathrm{J}, \mathrm{c}_{\mathrm{nw}}=0 ; \mathrm{J}>0 \mathrm{c}_{\mathrm{nw}}=0 ; \mathrm{J}, \mathrm{c}_{\mathrm{nw}}>0$ and no control; J, $\mathrm{c}_{\mathrm{nw}}>0$ with $\mathrm{PC}$ and $\mathrm{J}, \mathrm{c}_{\mathrm{nw}}>0$ with $\mathrm{PC}$ and $\mathrm{SC}$.

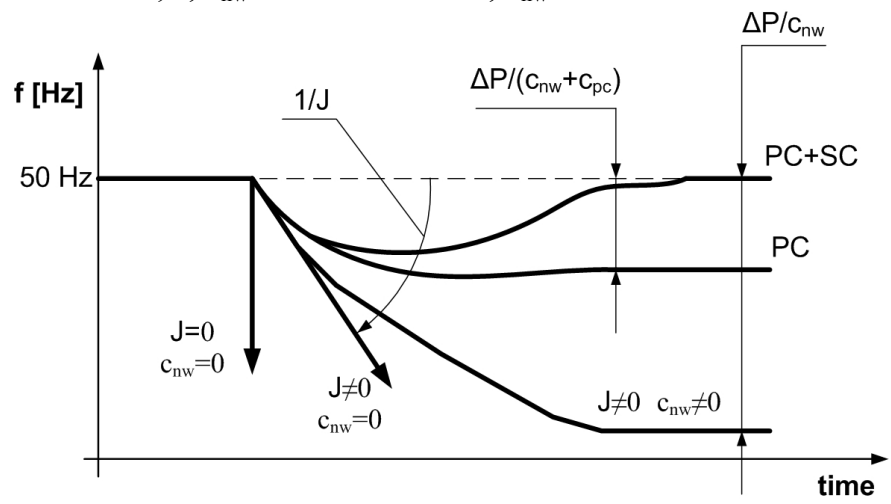

Fig. 3. Effect of load disturbance $\Delta \mathrm{P}[\mathrm{MW}]$ on frequency $\mathrm{f}$ depending on values $\mathrm{J}, \mathrm{c}_{\mathrm{nw}}$ and without/with $\mathrm{PC}$ and/or SC control active.

Drawbacks of present arrangements:

- $\quad P C$ is a useful and a necessary service for guaranteeing the stability of the power network. Still, it has to be enforced and yields only negative incentives and unreasonable costs for the BRP. Only strict enforcement by the TSO makes the PC available.

- The gains in PC and SC have to be dependent on the grid topology $\left(\mathrm{J}, \mathrm{c}_{\mathrm{nw}}\right)$, size of expected uncertainties and rate of load change, but they aren't.

- $\quad$ SC lets the TSO adjust the E -program in the actual PTU of the selected BRPs. However, the power needs not become available immediately as the BRP has only to satisfy its adjusted E-program in the PTU.

- The rule that BRPs have to satisfy their negotiated energy within a period of 15 minutes is too coarse. It will not help to stabilize the grid as the power can fluctuate considerably without violating any regulation.

- Especially, at the end of a PTU there are too many, often conflicting, control signals active that will influence the power balance: the necessity to control the demanded Eprogram in the PTU, and the actions from the PC en SC. The net effect is that up to $70 \%$ of the $\mathrm{PC}$ reserve capacity is used for this purpose, reducing this PC capacity for emergency situations to $30 \%$ of its intended value.

The effects of these drawbacks on the stability of the power balance cannot be predicted. It can introduce unwanted oscillations and even instability.

\section{NEW CHALLENGES}

For the future several developments indicate that energy markets and the power network will change and adapt to new technological, societal and economic developments.

A few of them:

- The synchronous grid will increase in size. With more generators and rotating loads the network constant $\mathrm{c}_{\mathrm{nw}}$ and $\mathrm{J}$ will increase. The same load change will introduce a smaller and slower frequency deviation. This is a positive development. Power-controlled DC-lines do contribute neither to $\mathrm{c}_{\mathrm{nw}}$ nor to $\mathrm{J}$.

- The grid will be used ever more for economic operation. That implies that quite some cross-border tie-lines are loaded up to their maximum. When they are at their maximum capacity, no control (emergency) power can be used from far away. Consequently, only that part of the grid connected with the area of the disturbance by unconstrained lines can contribute to deliver the needed power shortage [4,5]. By sacrificing some economic profits, sufficient spare capacity must be allocated on the relevant cross-border connections.

- Although the grid size increases, the physical connections (tie-line system) still pose a constraint on the allowed power flows. As a consequence, there will always be an upper limit for the amount of locally available emergency power and ancillary services. The spatial dimension of the grid really matters for AS [3-5].

- A considerable penetration of renewables is to be expected. Present policy is to increase to $30 \%$ wind and solar energy, which will introduce larger uncertainties and more demanding arrangements for AS.

- Many units become connected by power-electronic converters to the grid. As a consequence these generators and loads become purposely insensitive for the actual frequency and voltages of the network. The demanded or supplied power is realized, in spite of changing variables in the grid. That decreases the network constant $c_{n w}$ and the equivalent inertia of the network, resulting in less passive stability. When all loads and producers are connected by a power-controlled converter to the grid, so $\mathrm{J}=0$ and $\mathrm{c}_{\mathrm{nw}}=0$, the power system has become uncontrollable, as elucidated in Fig. 3.

- The dynamics of technical devices, control loops and market are starting to overlap, introducing unexpected and unintended "stability" problems, as elucidated at the end of a PTU with large frequency deviations of up to 150 $\mathrm{mHz}$ within a time frame of 10 minutes [10].

All, except the first, arguments will increase the sensitivity of the frequency $f(t)$ for uncertainties and disturbances.

\section{NEW ARRANGEMENTS FOR ANCILLARY SERVICES}

Required are incentives and rules to guarantee both a reliable and stable grid in spite of technological, economic and societal changes, competing BRPs, and cross-border trade. They have to guarantee low prices, high reliability, low sensitivity to the large uncertainties of renewables, low sensitivity to large, unexpected disturbances and sufficient incentives for 
upgrading the grid and the production capacity for future operations. This generic goal is not the natural aim of prosumers, neither of BRPs and even not of a TSO with respect to future situations. Nobody cares directly about the integrity of the power system on the long run. Still that goal has to be achieved to the benefit of all.

New operational arrangements, characterized by doublesided markets for ancillary services, represent a formal framework to optimally support the (non-formal, naturally occurring) decentralization processes that are already taking place in the system. They provide a platform for the operational structure in which the true economically optimal operation can be achieved as all potential benefits of the network will be optimally exploited.

It is important to note that, although the TSO could have better estimates of uncertainties in the system (and therefore for the AS needs) as it benefits more from the aggregation effects, the BRPs have more knowledge and more incentives for this estimation. These incentives include their desire for improving its time-varying uncertainty estimates as well as finding the optimal trade-offs between reliability and direct economic benefits. The TSO, as the only 'consumer' of AS, has a monopoly and its only incentive is to be on 'the secure side', even if this security implies utilization of over conservative and far from optimal solutions.

Therefore, we propose as additions to the already existing ahead markets for energy, new ancillary services markets which are open, transparent with sufficient liquidity and with proper regulation which can give sufficient incentives for an economic and reliable power system, as elucidated in Fig. 4. The ancillary services markets are ahead markets to cope with uncertainties as expected before operation. The quantities traded are capacities [MWh] to deliver energy within some time interval when needed. They can, but in general will not, be called into operation. BRPs assess their uncertainties and liabilities. They define their own reserve capacity for PC, SC and $\mathrm{TC}$ for the expected uncertainties in their production or demand. Any excess or deficit can be traded on an AS market. If the AS markets yields a cheaper solution compared with its own solution (e.g. switchable or adjustable loads), the BRP can select the market.

Remark 6: Emergency situations will rarely occur but if they occur it may hamper a BRP considerably. It has to do with a trip of a large unit or part of the grid. To cope with these disturbances is too difficult for a BRP. For this type of situations, the grid may give the best solution, as it shares the risks of an event with very low probability, but large consequences.

This paper focuses on the Ancillary Services markets $[1,2,6,8]$. Each BRP has to define its expected production $P_{k}$ and consumption $D_{k}$ of energy for each considered PTU k. The difference has been guaranteed by trading on the energy market (APX). However, both quantities $\mathrm{P}_{\mathrm{k}}$ and $\mathrm{D}_{\mathrm{k}}$ are connected with uncertainties. Assuming a known correlation among all uncertainties, the BRP can decide about its overall uncertainty, separately for producing too much/too less

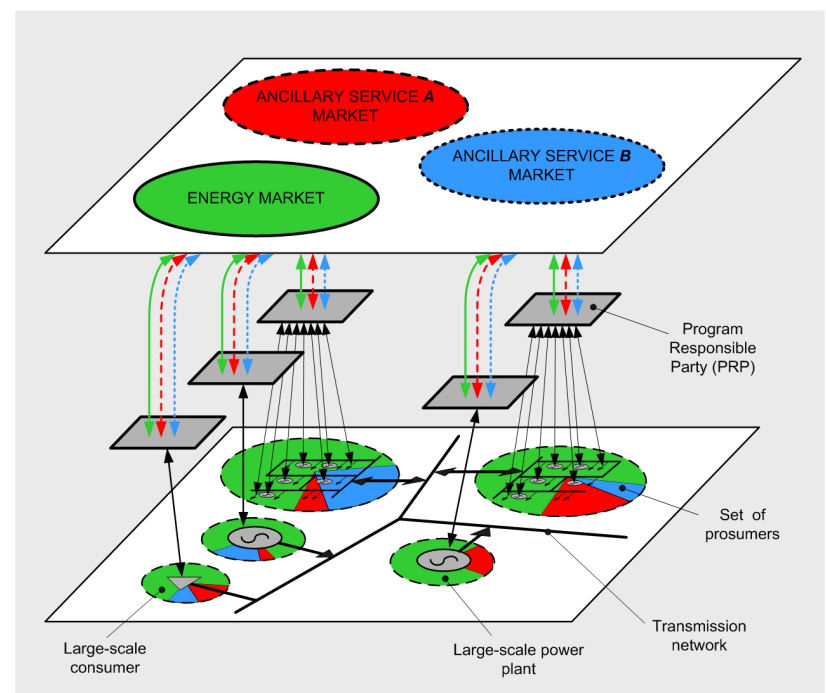

Fig.4. Energy and ancillary services markets.

consumption $\left(\mathrm{R}^{+}\right)$or producing too little/too much consumption $\left(\mathrm{R}^{-}\right)$. As these quantities are a function of price $\lambda$, each BRP will have for each PTU $k$ two demand graphs $\lambda_{k}\left(R^{+}\right)$ and $\lambda_{k}\left(R^{-}\right)$, both only defined between the constraints

$\mathrm{R}_{\text {min }}^{-} \leq \mathrm{R}^{-} \leq 0 \leq \mathrm{R}^{+} \leq \mathrm{R}_{\text {max }}^{+}$. The prices reflect the maximum affordable price for buying capacity. If the market price $\lambda^{\mathrm{AS}}$ is higher, own alternatives have to be found, as the market is not willing to supply the required services for the stated maximum price. If the market price $\lambda^{\mathrm{AS}}$ is lower, the market offers a cheaper solution than own alternatives. The same BRPs can assess their capabilities for supplying ancillary services. Two different supply bid graphs for supplying power $\lambda_{k}\left(\mathrm{~S}^{+}\right)$and for receiving power $\lambda_{\mathrm{k}}\left(\mathrm{S}^{-}\right)$can be constructed to formulate the willingness to supply ancillary services. These prices reflect the minimum price $\lambda_{\mathrm{k}}\left(\mathrm{S}^{+-}\right)$[€/MWh] for which the required capacity $\mathrm{S}[\mathrm{MWh}$ ] will be made available when demanded. When the market price $\lambda^{\mathrm{AS}}$ is lower, the BRP is not willing to supply the desired quantity of ancillary service.

A market agent (MA) may collect these bids from all participating BRPs $\mathrm{i}$ and for all periods $\mathrm{k}$ and aggregate them into 2 final curves: the graphs $A: \lambda^{A}{ }_{k}(R)\left\{\lambda_{k}\left(R^{+}\right), \lambda_{k}\left(S^{-}\right)-\right.$ demanding capacity to absorb too much power $\}$ and $\mathrm{B}$ : $\lambda^{\mathrm{B}}{ }_{\mathrm{k}}(\mathrm{R})\left\{\lambda_{\mathrm{k}}\left(\mathrm{R}^{-}\right), \lambda_{\mathrm{k}}\left(\mathrm{S}^{+}\right)\right.$- demanding capacity to supply the lack of power\}. Then, for each PTU k, separately for A and B, prices $\lambda^{\mathrm{A}}$ and $\lambda^{\mathrm{B}}{ }_{\mathrm{k}}$ are determined such that there is a balance between the required (R) and reserved/supplied (S) ancillary services $(2,3)$ :

$\sum_{i}\left\{R_{i}^{+}\left(\lambda_{k}^{A}\right)+S_{i}^{-}\left(\lambda_{k}^{A}\right)\right\}=0$
$\sum_{i}\left\{R_{i}^{-}\left(\lambda_{k}^{B}\right)+S_{i}^{+}\left(\lambda_{k}^{B}\right)\right\}=0$

Ultimately the buyer/seller of the ancillary service has to pay/will receive an agreed price. This price is a predefined function of the prices $\lambda^{\mathrm{A}}{ }_{\mathrm{k}}$ and $\lambda^{\mathrm{B}}{ }_{\mathrm{k}}$ and the APX price $\lambda^{\mathrm{APX}}{ }_{\mathrm{k}}$ for energy. The price for demanding/selling capacity when it is not used can be formulated, for example $\mathrm{x} \%$ of $\lambda^{\mathrm{A}}{ }_{\mathrm{k}}$ and $\lambda^{\mathrm{B}}{ }_{\mathrm{k}}$. A requirement for a unique market solution is that the graphs $\lambda_{\mathrm{k}}\left(\mathrm{R}^{-}\right)$and $\lambda_{\mathrm{k}}\left(\mathrm{S}^{+}\right)$are monotonously non-decreasing and that the bid graphs $\lambda_{k}\left(R^{+}\right)$and $\lambda_{k}\left(S^{-}\right)$are monotonously non- 
increasing. These bid graphs of a BRP are elucidated in Fig. 5.

With these prices there are unique combinations of BRPs which agree to prosume their offered bid when needed.

The price functions have to be selected to enforce a reliable, acceptable solution for the global power system. A reasonable requirement will be: $\lambda_{\mathrm{k}}^{\mathrm{APX}}<\lambda_{\mathrm{k}}^{\mathrm{AS}}<\lambda_{\mathrm{k}}^{\text {imbalance }}$.

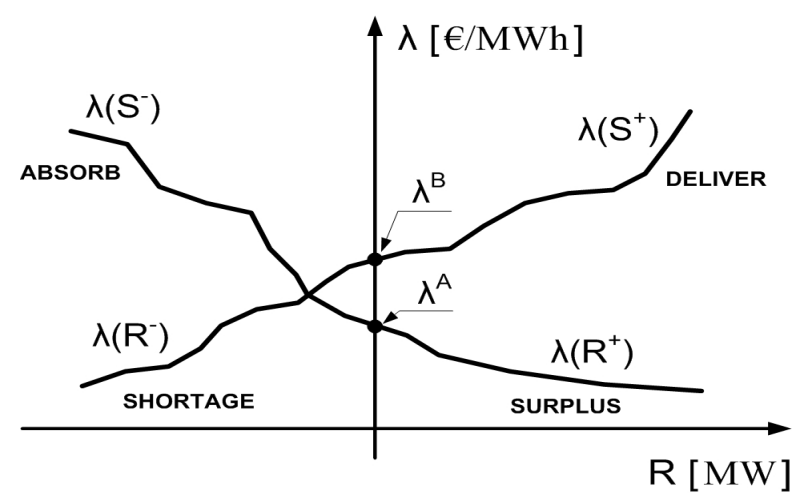

Fig. 5. Aggregated bids of a BRP as a function of price $\lambda[€ / \mathrm{MWh}]$ with $\lambda \mathrm{A}(\mathrm{R})\{\lambda(\mathrm{R}+), \lambda(\mathrm{S}-)\}$ and $\lambda \mathrm{B}(\mathrm{R})\{\lambda(\mathrm{R}-), \lambda(\mathrm{S}+)\}$.

When these proposed AS markets are available and all BRPs participate, this market mechanism can replace present control strategies. In any case the SC and, dependent on the speed of information exchange, a part or all PC can be replaced by the AS markets. In [2-4] it is shown that when the market dynamics are comparable with the power system dynamics, price-based control is a realistic option and can replace PC and (parts of) SC. If implemented, BRPs have the incentives to make economic viable decisions about power and ancillary services. If the SC is being replaced, the TSO still has to operate at the AS markets for guaranteeing the control areas requirements on frequency, cross-border power deviations and emergency situations. Network constraints introduce one-sided restrictions for AS. So, the degree of AS is not homogenously distributed among the network, but discretely different. Also nodal pricing is needed when network restrictions occur [4,5]. The theory presented in $[9,11]$ has potential for devising novel distributed control schemes for optimal secondary control of the future European power network. As a BRP has the best local information of its production and demand, it is the perfect party to decide and make trade-offs whether to offer its production/demand on either the power or on the AS markets. The proposed AS markets guarantee the most cost-effective and reliable solution for the ancillary services $[2,9,11]$.

\section{ANCILLARY SERVICE CLASSES}

Ancillary services are defined as capacities, namely the ability to deliver energy in a predefined (short) time interval. Generating immediately power within seconds/minutes when demanded requires dedicated, expensive power sources, for example batteries, flywheels, spinning reserve, UPS, switchable or adjustable loads, e.g. in market gardening of flowers and vegetables, aluminum forge, cooling and freezing companies. When there is a proper incentive, the loads can and will be adjusted, also in the $400 \mathrm{M}$ domestic loads. With faster reaction, higher costs are to be expected. For these reasons we introduce AS in several classes $[8,12]$. Each class $p, p=1, P$, is being characterized by its response time $t_{p}[s]$ : within $t_{p}[s]$ the requested energy has to be delivered. A bid for the AS market $p$ is characterized by its price $\lambda_{\mathrm{p}}(\mathrm{R})[€ / \mathrm{MWh}]$ as function of its capacity R [MWh], between its minimum and maximum values, being made available. Keeping power available when needed is beneficial for the power system and has to be rewarded. In defining classes for AS it is a necessity to guarantee sufficient liquidity (trade volume) and sufficient BRPs for guaranteeing a transparent market.

Once for each AS market $p$ and PTU $k$ the contributions and a price are settled, each BRP $i$ knows how much capacity $\left(\mathrm{S}^{+/-}\right.$ pik) of each class $p$ it has to keep available for or can count on $\left(\mathrm{R}^{+/}\right.$pik $)$from the market and for which prices $\lambda^{\mathrm{AS}}{ }_{\mathrm{pk}}$.

When AS is needed by a BRP, which is easily to be detected as its net contribution to the grid deviates from the agreed contribution, it can inform the TSO for additional AS, both classes and sizes (plural, as the expected disturbance can cover timeslots of several classes). The TSO may ask the BRP which had offered the cheapest AS to release the required quantity. The asking BRP has to pay the agreed price (which is lower than its maximum price) and the supplying BRP will receive a price (which is higher or equal than its offered price). So both BRPs experience a financial profit. A Market Agent (MA) can take care of all accounting issues concerning bids, prices, and realized AS.

\section{CONCLUSION}

The present arrangements for power system integrity show insufficient and inconsistent incentives for BRPs and TSOs to behave in such a way that a reliable and economic future power system is guaranteed. The introduction of markets for ancillary services enforces that the estimation of the size and the character of these services are determined by the BRPs themselves. The BRP takes the decision to distribute its resources among the several markets. The proposed AS markets guarantee the most cost-effective and reliable solution for the ancillary services. A power system equipped with these AS markets is well prepared for the many challenging new developments in the near future.

\section{ACKNOWLEDGMENT}

We appreciate the stimulating and rewarding discussions in the EOS RegelDuurzaam research project.

\section{REFERENCES}

[1] Stoft, S., Power System Economics: Designing Markets for Electricity, Kluwer Academic Publishers, 2002.

[2] Alvarado, F.L., Meng, J., DeMarco, C.L., Mota, W.S., Stability Analysis of Interconnected Power Systems with Market Dynamics, IEEE Transactions on Power Systems, 16 (4), pp. 695-701., 2001.

[3] Alvarado, F.L., Understanding Locational Reserves and Reliability Needs in Electricity Markets, Hawaii 
International Conference on System Sciences, USA, 2006.

[4] Jokic, A., M. Lazar, P.P.J. van den Bosch, Real-Time Control of Power Systems Using Nodal Prices, $16^{\text {th }}$ Power Systems Computation Conference (PSCC 2008), Glasgow, UK, July 2008.

[5] Christie, R.D., Wollenberg, B.F., Wangensteen, I., Transmission Management in the Deregulated Environment, Proceedings of the IEEE, 88 (2), pp. 170195., 2000.

[6] Frunt, J., A. Jokic, W.L. Kling, J.M.A. Myrzik, P.P.J. van den Bosch, Provision of Ancillary Services for Balance Management in Autonomous Networks, 5th International Conference on the European Electricity Market, Lisbon, Portugal, May 2008.

[7] DeMarco, C.L., Control Structures for Competitive, Market-driven Power Systems, IEEE Conference on Decision and Control, 2001.

[8] Jokic, A. Price-based Optimal Control of Electrical Power Systems, $\mathrm{PhD}$ thesis, Eindhoven University of Technology, Eindhoven, The Netherlands, 2007.

[9] Jokic, A., Lazar, M., On Stabilization of Discrete-time Nonlinear Systems under Arbitrary Information Constraints, IEEE Transactions on Automatic Control, Submitted for publication, 2008.

[10] Tractabel Engineering, Study of the Interaction and Dependencies of Balancing Markets, Intraday Trade and Automatically Activated Reserves, Feb 2009. http://ec.europa.eu/energy/gas_electricity/ studies/doc/electricity/2009_balancing_markets.pdf

[11] Jokic, A, R.M. Hermans, M. Lazar, P.P.J. van den Bosch, Distributed, price-based control approach to marketbased operation of future power systems, Proceedings 6th International Conference on the European Electricity Market, Leuven, May 2009.

[12] Frunt, J. Student Member, IEEE, W.L. Kling, Member, IEEE, J.M.A. Myrzik, Member, IEEE, Classification of Reserve Capacity in Future Power Systems, Proceedings 6 th International Conference on the European Electricity Market, Leuven, May 2009. 